\title{
Defining Archetypes and Requirements for mHealth Interventions in Rural Kenya: An Investigation in Collaboration with CURAFA ${ }^{\mathrm{TM}}$
}

\author{
Danielly de Paula \\ Hasso Plattner Institute \\ danielly.depaula@hpi.de
}

\author{
Jan Zarske Bueno \\ University of St. Gallen \\ jan.zarskebueno@student.unisg.ch
}

\author{
Altus Viljoen \\ Technical University of Munich \\ altus.viljoen@tum.de
}

\begin{abstract}
Designing and implementing successful mobile health (mHealth) applications is always challenging, but even more so in countries and communities in rural areas where the target population have access to limited resources. While some mHealth initiatives have shown success and potential in Kenya, still too many fail. One of the reasons for failure is the limited understanding of the health-seeking behavior and social-technological context of the rural Kenyan population. This study aims to use a mixed-method approach to define archetypes of rural Kenyan patients and translate them into requirements which can guide the design and implementation of user-centric mHealth interventions in rural Kenya. With this study, we show how practitioners can leverage existing organizational and social structures in developing countries to develop mobile health applications tailored to patients' needs.
\end{abstract}

\section{Introduction}

In developing countries, millions of people lack accessible and affordable healthcare [1]. Kenya is no different, with a doctor-to-patient ratio of 1.5 to 10,000 , as opposed to the World Health Organization's (WHO) recommendation of 36 to 10,000 [2]. However, as prevalence and access to mobile phones in developing countries have become ubiquitous, mHealth - the use of mobile phone technology for health-related purposes - has gained popularity in enabling and advancing access to affordable healthcare [3]. In Kenya, 97.8\% of the adult population have access to a mobile phone (including both feature and smartphones), leading to the Kenyan government's eager exploration of strategies for the adoption, implementation and cost-effective utilization of mHealth initiatives through its Kenya National eHealth Policy 2016-2030 [4, 5].

While many mHealth initiatives have shown success and potential in Kenya, there are still many that fail, and establishing the causes of such mHealth failures has been the subject of research [6]. Especially in developing countries, inattention to the attitudes and behaviors related to technology use has been an impediment to device acceptance and scalability $[7,8]$.

Kenya - a country with a rural population of $72.5 \%$, 47 counties, and wide-ranging health issues [9] - poses a complex, challenging, and diverse environment with a wide range of possible user types and applications. In order to successfully accommodate the heterogeneity of users, scholars recommend identifying specific types of individuals with specific needs through archetypes as well as user requirements [10]. In the mHealth context, the application of user-centered design and its attributes - specifically archetypes - have been found to allow researchers to highlight the diversity of the user base in a manageable and actionable way [11].

However, archetypes alone are not sufficient to develop mHealth interventions - it is also necessary to translate them into user requirements in order to properly guide developers and designers [12]. While research has been conducted on the definition of design archetypes for mHealth development in general, the definition of design archetypes and user requirements specifically for marginalized and hard-to-reach target users have been neglected $[11,13]$.

In response to these problems, this study uses a mixed-method approach to define archetypes of rural Kenyan patients and translate them into requirements to guide the design and implementation of user-centric mHealth interventions in rural Kenyan. In this paper, we discuss how the creation of these archetypes can augment the existing literature on technology acceptance and inform technology development in low-resource settings [14]. The following two research questions guided this study:

RQ1: What are the main archetypes of patients for mHealth development in rural Kenya?

RQ2: What requirements for mHealth in rural Kenya can be derived from these archetypes?

Finally, in addition to the archetypes and requirements generated from RQ1 and RQ2 through 
the mixed-method approach, recommendations are also given of how mHealth developers can utilize these insights to design effective mHealth interventions in settings where similar challenges are present, be it in developing countries in Africa or beyond.

\section{Literature Review}

The study aims to provide mHealth developers and designers with clear and practical archetypes and requirements relevant to the rural Kenyan environment. In order to construct these, as well as to develop an appropriate methodology, insights from traditional technology acceptance theories and the specific challenges for mHealth development in Kenya are reviewed and synthesized.

\subsection{Technology Acceptance Models: Constructs for Resource Limited Settings}

Investigating theories and models that can be used to predict and explain user behavior across many domains has been extensively studied in information systems (IS) research [15]. Although traditional technology acceptance models addressing behavioral change - such as the technology acceptance model (TAM) [16], the unified theory of acceptance and use of technology (UTAUT) [17], and its extension (UTAUT2) [18] offer a solid starting point for mHealth developers, they do not address unique social, cultural and behavioral factors that are specific to Resource Limited Settings (RLS). Especially in RLS such as Kenya, where health-seeking behavior is low and influenced by complex socio-cultural determinants unique to the RLS [19], behavioral change in terms of health-seeking behavior is thus of utmost importance.

Accordingly, authors [20] proposed a conceptual model to help better understand the predictors of user acceptance of health information technology at the patient-level in developing countries. This model is based on TAM, which is the most widely used model in the mHealth and broader eHealth research [21]. TAM posits that perceived usefulness and perceived ease of use of a technology predict the intention to its use [16]. In addition to the core constructs of TAM, the authors [20] propose perceived cost-effectiveness as a relevant additional construct consisting of four drivers: (i) medication, (ii) transportation, (iii) loss of time, and (iv) loss of productivity. In a more recent study, scholars [14] developed a context-specific conceptual technology acceptance model for RLS (TAM-RLS). This was developed along with the utilization of SMS interventions for HIV patients in Uganda. In addition to the constructs of TAM, TAM-RLS proposes confidentiality as a possible driver of acceptance.

Overall, the literature reveals predictors of mHealth acceptance among end-users in RLS, which can be summarized in four constructs, namely: (i) perceived usefulness, (ii) perceived ease of use, (iii) perceived cost-effectiveness, and (iv) confidentiality. However, while these predictors offer relevant insights that researchers and practitioners need to take into consideration when developing mHealth interventions, they do not provide more personal and context-specific insights into the mHealth development process as such. More specifically, it is important to understand the behaviors of a specific group of users (or archetypes) in order to infer design requirements that can be targeted to these user groups.

\subsection{Challenges for mHealth Adoption in Kenya and other RLS in Africa}

While the previous section details the factors found to affect user acceptance of technology in RLS, many general healthcare challenges faced by patients can also impact successful mHealth adoption - while many mHealth interventions in Kenya have shown to be effective, uptake and continued use of mHealth remains a challenge [22]. This section addresses these issues.

Technological challenges for Kenyans entail, among others, access to smartphones and shared usage of mobile phones [23]. While $97.8 \%$ of the Kenyan adult population have access to a mobile phone [4], smartphone penetration of Kenya's populations stands at only $30 \%$ [24]. Older patients also tend to use basic mobile phones [25], which lacks the functionality to run mHealth applications [26]. While 85\% of Kenyans indicated that they use a mobile phone, only approximately $44 \%$ owned their phone [23].

Economic challenges also hinder mHealth adoption [27] - not only the cost of obtaining a mobile device, but also that of maintaining an internet connection to sustain the use of a mobile application Moreover, it was found that poorer Kenyans spend a disproportionate amount of their income on airtime [23], worsening the accessibility for patients who often need mHealth interventions the most.

Educational factors, such as low levels of education and technological illiteracy also impact mHealth adoption [28]. In Kenya, educational divides are also reflected in mobile phone ownership, as only $18 \%$ of less-educated Kenyans own a smartphone, compared to $62 \%$ of their more educated counterparts [24].

Socio-cultural factors include multiple considerations for successful mHealth applications, their development and adoption, and are often unique to 
the specific target user demographic for an intervention. Lack of multilingual content and interface for the target user may also lead to sub-par adoption of the mHealth interventions [28], and, unsurprisingly, it has been found that mHealth projects have proved to be more successful when adapted to the local context and language $[6,29]$. Additionally, especially in RLS, patients often place a premium on personal contact with medical practitioners, meaning that, for patients, the insufficiency of face-to-face interaction and user perception act as potential barriers to the adoption of mHealth interventions [28].

\subsection{Shifting to Patient-Centric mHealth Design for the Rural Kenyan Context}

It is important to mention that this study does not intend to develop a theoretical adaption of a technology acceptance model. Instead, this study proposes to depart from such an outcome by addressing two gaps identified in previous literature.

Firstly, while the constructs and drivers derived from technology adoption models tailored to RLS offer valuable insights, they remain high-level and have not yet offered any practical advice for mHealth developers to consider when designing interventions for the rural Kenyan environment. Especially in RLS, it is crucial to consider these contextual-specific "downstream barriers" when designing mHealth solutions. For instance, authors [30, 31] state that when designing mHealth interventions, it is important to understand the context-specific goals and motivations of the target population and their healthcare context. Lacking this understanding can lead to failures as mentioned in [6]. In addition, it became evident that when designing mHealth interventions, especially in developing countries, it is necessary to consider the financial-technological context of the population [27, 32]. For instance, by understanding the technological adoption of patients, authors [32] managed to propose mHealth interventions that improved medication adherence. We thus propose the inclusion of these two dimensions - healthcare context and financial technological context - when developing requirements for mHealth developers.

Secondly, unlike studies that have validated technological acceptance models purely quantitatively, [25, 33], key learnings such as in TAM-RLS are more likely to emerge from qualitative approaches [14], especially through interviews which can elicit anecdotes from patients. Moreover, a user-centered design approach, and especially archetypes developed through mixed-method user research, is particularly useful to communicate to developers the needs of marginalized or hard-to-reach target users [34, 35, 36]. Additionally, archetypes that leverage biopsychosocial data from multi- or mixed-method inquiry have been found to be not only an appropriate, but also a largely underutilized component of current mHealth developments [36]. The authors argue that such a mixed-method, user-centered approach has the potential to generate more personalized findings which may prove useful for developing design requirements for mHealth developers.

\section{Research Methodology}

This study followed a three-step approach involving research, modeling, and the definition of requirements, as proposed by [10]. The research phase started with a literature review aimed at understanding the current challenges faced by healthcare patients in Kenya, and the literature review on predictors for technology acceptance for mHealth development in low-resource areas of developing countries. A quantitative survey was then conducted to collect context-specific behaviors and the health needs of patients in rural Kenya. In the modeling and requirement phase, patients in Kenya were personally interviewed. As a result, an archetype framework was created. Finally, user requirements were derived based on the interviews by following the steps for designing mHealth for developing countries as explained in [12]. Methodologically, we followed an explanatory mixed-method design [37] where the results of a survey (quantitative) help inform an in-depth investigation (qualitative) using semi-structured interviews.

\subsection{Research Phase: Preliminary Quanti-Study}

To characterize the population of rural Kenya, a survey was created aimed at investigating the patients' socio-economic circumstances, healthcare satisfaction, and mobile phone adoption. The survey was conducted with patients at a CURAFA ${ }^{\mathrm{TM}}$ health camp base located in Machakos in September 2019. The health camp offers free consultation and health check-ups for the local population. The survey items were derived from the technology acceptance literature, and mHealth interventions in RLS literature. All items were adapted to the context of this study. To ascertain content validity, the items were validated with researchers who are experts in using human-centered design to develop interventions in low-resource settings, as well as Merck $\mathrm{KGaA}$ employees from the headquarters and local office in Nairobi, Kenya. In addition, face validity of the 
questions was tested with locals in Kenya. The survey included 14 questions which covered five parts, (i) demographic data, (ii) healthcare context, (iii) mobile technology adoption, (iv), interest in mHealth, and (v) financial spending behavior. In total, 51 health camp participants answered the survey. Questions were answered on a 5-point Likert scale, ranges and/or check boxes. The data was analyzed and used to develop a semi-structured interview guide to gain additional in-depth insights.

\subsection{Modeling and Requirement Definition}

In total, 36 semi-structured interviews were conducted in December 2019 when one of the authors visited Kenya for two weeks. The interviews aimed to deepen our knowledge in terms of the population's socio-economic circumstances, healthcare context, and mobile phone adoption. An interview guide was derived both from the literature and from the results of the quantitative study. Interviewees from three counties - Kiambu, Kajiado, and Machakos - were purposely selected via the CURAFA ${ }^{\mathrm{TM}}$ points-of-care pharmacies established in these locations. Not all interviewees were CURAFA ${ }^{\mathrm{TM}}$ patients. All interviews were audio-recorded and transcribed. After completion of the field research, the steps for the creation of archetypes proposed by [10] were followed.

First, the transcripts were analyzed in order to identify and map behavioral variables, which were categorized into patterns as follows: the coding of the transcripts resulted in $641^{\text {st }}$ order codes from which $232^{\text {nd }}$ order codes were derived, following the Gioia Methodology [38]. The average length of interviews was 37 minutes and 52 seconds. Open Coding technique [37] was employed, using the qualitative data analysis software NVIVO 10. The analysis of the data revealed significant aspects which help understand the characteristics of patients in rural Kenya. Then, following [10], we defined the goals of each archetype. In this way the data was used to inform the creation of the four archetypes. As a result, we created the first version of an archetype framework.

In order to refine the archetype framework and expand the description of the attributes and behaviors as recommended by [10], the same author made a second field trip to Kenya in February 2020 to conduct 42 semi-structured interviews. The goal was to evaluate aspects of the previously defined archetypes that seemed to be critical, and also to investigate whether the interviewees could be categorized into the archetypes. The data was then analyzed and coded by following the same steps mentioned before. As a result, the refined archetype framework can be seen in Figure 1. All 42 interviewees were categorized into the framework. Finally, after refining the archetypes, their characteristics were translated into requirements (see Table 1) [12]. To facilitate the replicability of the study, we created a public online folder ${ }^{1}$ containing the survey questions (Digital Appendix A), and the interview guide for the first trip (Digital Appendix B).

\section{Results}

\subsection{Characterizing the Population in Rural Kenya}

The questionnaire survey conducted with 51 patients elicited the socio-economic circumstances, healthcare context, and mobile phone adoption of the local population.

The demographic-healthcare context. In total, 44 of the respondents were women, and the average age of participants was 47 years $(S D=20.3)$. The highest level of educational achievement was a primary school degree for $44 \%$ of participants, followed by a high school degree for $24 \%$ of participants, whereas $23 \%$ had left school without a qualification.

When asked about how satisfied they were with their current medical care, $69 \%$ of participants answered that they were satisfied. When asked about their last visit to a professional healthcare facility, $45 \%$ of patients answered that they were very satisfied with the information they received. In terms of accessibility of medical care, $59 \%$ of participants found it easy $(49 \%)$ or very easy $(10 \%)$ to receive medical care as opposed to $19 \%$ who found it difficult or $12 \%$ who found it averagely difficult. Major reasons were lack of knowledge where to get appropriate healthcare (51\%), costs for traveling to a healthcare facility (17\%) or costs for receiving healthcare (12\%).

The financial-technological context. When asked about mobile technology adoption, our results show that most participants (45\%) had a feature phone and some of them (27\%) a smartphone. When asked about their interest in using mHealth, $51 \%$ of the participants were undecided, $22 \%$ stated that they were likely to use a phone to receive medical care, while $21 \%$ were unlikely to do so. In terms of mobile technology usage, $18 \%$ of participants said they use their smartphone more than once or twice a day. When asked about their average spending power, $31 \%$ of the participants have average monthly expenditures of 3,000 to 5,000 Kenyan Shillings (KES) (approximately 30-50 USD), 29\% of participants of only between 1,000 and 3,000 KES, and

\footnotetext{
${ }^{1}$ https://bit.ly/3jr1gK2
} 
$20 \%$ of between 5,000 and 7,000 KES. Total healthcare spending is less than $500 \mathrm{KES}$ (approximately 5 USD) for $74 \%$ of the participants. The preferred method of payment remains cash in the participant group with only $2 \%$ having a preference for mobile payments (e.g. M-Pesa).

\subsection{Archetypes Framework for mHealth Development in Rural Kenya}

Figure 1 proposes our two-dimensional archetype framework with both dimensions being dichotomized from low to high. It is important to note that the concept of low and high is relative to the environment. Both dimensions were derived from the literature review as discussed below.

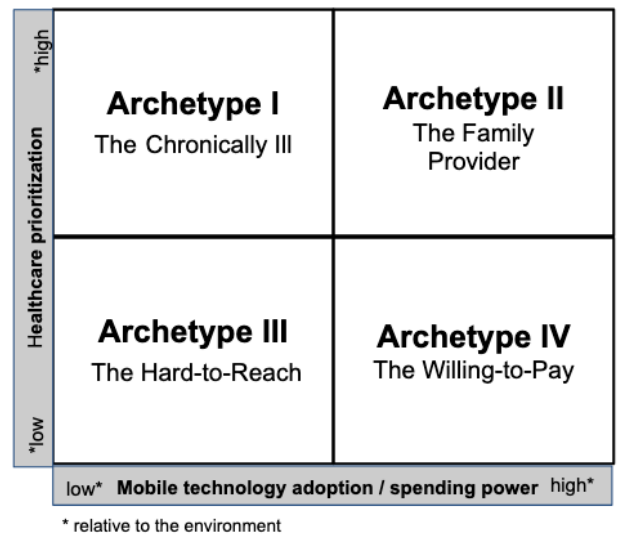

Figure 1: Archetypes Framework

In our framework, the dimension "healthcare prioritization" aims to understand the health-seeking behavior of the patients in order to define the purpose of the mHealth interventions. As mentioned in the literature review section, this argumentation is supported by $[30,31]$. The dimension "mobile technology adoption/spending power" constitutes factors related to patients' access to mobile phones, willingness to use mHealth, and their average spending power for healthcare. It illustrates the financial technological context of the sample, which is supported by [27, 32]. Thus, we propose that "healthcare prioritization" and "mobile technology adoption/spending power" are essential for classifying archetypes for mHealth in developing countries.

Based on this knowledge, we categorized our archetypes into: Archetype I (AI), The Chronically Ill, Archetype II (AII), The Family Provider, Archetype III (AIII), The Hard-to-Reach, and Archetype IV (AIV), The Willing-to-Pay. Table 1 illustrates factors related to each archetype, which offers insight into user behaviors in rural Kenya that may be used to inform the design and implementation of mHealth interventions in this population. For each archetype, we explain their life goals (wants to be), end goals (wants to have), and experience goals (wants to feel), and pain points as recommended by researchers [10]. It is worth noting that archetypes' needs can overlap (see common needs in Table 1) and that archetypes' characteristics are not always mutually exclusive.

AI: The Chronically Ill. This archetype illustrates a patient who has been diagnosed with a chronic condition and has low financial means to pay for healthcare and smartphones with a data plan. This archetype wants to have regular medical care treatment and communication with a group support, and also wants to feel more empowered about the disease. This archetype represented $41 \%$ of the conducted persona refinement interviews ( $22 \%$ male, $78 \%$ female). However, due to the low income and the lack of access to information about their disease, it is difficult to know how to change their lifestyle in order to reduce the impact of the disease on their daily life. Moreover, this archetype wants to be strong and healthy. As one interviewee claimed, "I want to be treated, so I can have a long life, have less pain, feel good and do all my things". The pain points are: (i) lack of a regular medical treatment for her, (ii) lack of awareness of how to reduce the impact of her disease on her daily life, and (iii) the burdens of psychological stress due to her advanced age, serious health conditions, and low financial means.

AII: The Family Provider. This archetype illustrates a patient whose priority is to find a way to get healthcare treatment for the family. This archetype represented $34 \%$ of the conducted persona refinement interviews (50\% male, $50 \%$ female) and is open towards using a smartphone for healthcare. According to one of the interviewees, "That would be great, that would be great! At least, it is in my hands, I just need to access it". This archetype wants to have a package solution for a fixed price (monthly or yearly payment) that includes healthcare for the family, and wants to feel in control of the healthcare treatment of their family. As one interviewee said, "It's very important to know the health status of every family member. You should know when things are small because they grow big fast". This also includes having access to the history of diseases of the family. Finally, this archetype wants to be updated by a trusted professional with the latest status of the health of the family. The pain points are: (i) not being able to provide proper healthcare for the family, (ii) not having details about the health conditions of the family, (iii) not being able to prevent common illnesses, such as cough. 
Table 1: Archetypes Overview

\begin{tabular}{|c|c|c|c|c|}
\hline Archetype features & $\begin{array}{l}\text { Archetype } \\
\text { The } \\
\text { Hard-to-Reach }\end{array}$ & $\begin{array}{l}\text { The Family } \\
\text { Provider }\end{array}$ & $\begin{array}{l}\text { The Chronically } \\
\text { Ill }\end{array}$ & $\begin{array}{l}\text { The } \\
\text { Willing-to-Pay }\end{array}$ \\
\hline \multicolumn{5}{|l|}{ Lifestyle factors } \\
\hline & $\begin{array}{l}\text { Limited support to } \\
\text { lead active lifestyle }\end{array}$ & $\begin{array}{l}\text { Active lifestyle } \\
\text { and advocate for } \\
\text { good health }\end{array}$ & Inactive lifestyle & $\begin{array}{l}\text { Active lifestyle, } \\
\text { both physically } \\
\text { and socially }\end{array}$ \\
\hline Income & Low & Intermediate & Low & High \\
\hline \multicolumn{5}{|c|}{$\begin{array}{l}\text { Health care } \\
\text { prioritization } \\
\text { and needs }\end{array}$} \\
\hline $\begin{array}{r}\text { Health care } \\
\text { coverage }\end{array}$ & No & $\begin{array}{l}\text { NHIF/publicly } \\
\text { insured }\end{array}$ & $\begin{array}{l}\text { NHIF/publicly } \\
\text { insured }\end{array}$ & $\begin{array}{l}\text { Privately insured } \\
\text { by NHIF }\end{array}$ \\
\hline $\begin{array}{l}\text { Health care } \\
\text { seeking }\end{array}$ & Low priority & High priority & High priority & $\begin{array}{l}\text { Intermediate } \\
\text { Priority }\end{array}$ \\
\hline \multicolumn{5}{|l|}{$\begin{array}{l}\text { Mobile phone } \\
\text { adoption and } \\
\text { purchasing power }\end{array}$} \\
\hline $\begin{array}{r}\text { Type of mobile } \\
\text { phone }\end{array}$ & Feature phone & Smartphone & Feature phone & Smartphone \\
\hline $\begin{array}{r}\text { Level of interest } \\
\text { in mHealth }\end{array}$ & Low & High & Intermediate & High \\
\hline $\begin{array}{r}\text { Purchasing power } \\
\text { (for healthcare) }\end{array}$ & Low & High & Intermediate & High \\
\hline Common needs & \multicolumn{4}{|c|}{$\begin{array}{l}\text { To have a close relationship with a trusted advisor for personal healthcare and } \\
\text { communication in local language (Trust and communication) } \\
\text { Reduce waiting and traveling times (Time) } \\
\text { Awareness of how to reduce the impact of the disease and/or to prevent diseases } \\
\text { (Education) }\end{array}$} \\
\hline $\begin{array}{l}\text { Primary } \\
\text { individual need }\end{array}$ & $\begin{array}{l}\text { Wants to have a } \\
\text { cheap healthcare } \\
\text { solution and } \\
\text { maintain routine }\end{array}$ & $\begin{array}{l}\text { Wants } \\
\text { information } \\
\text { from a trusted } \\
\text { source about his } \\
\text { family's health }\end{array}$ & $\begin{array}{l}\text { Wants daily } \\
\text { tailored content } \\
\text { on how to } \\
\text { decrease the } \\
\text { daily suffering } \\
\text { from NCD }\end{array}$ & $\begin{array}{l}\text { Wants easy } \\
\text { accessibility to high } \\
\text { quality healthcare } \\
\text { services/medicines }\end{array}$ \\
\hline Example quotes & $\begin{array}{l}\text { "You cannot } \\
\text { manage health if } \\
\text { you are hungry - } \\
\text { you need to feed the } \\
\text { family first. } \\
\text { Sickness is an } \\
\text { emergency, being } \\
\text { hungry is a } \\
\text { permanent } \\
\text { problem." (FT2.U3) }\end{array}$ & $\begin{array}{l}\text { "Very important } \\
\text { to know health } \\
\text { status of every } \\
\text { family member. } \\
\text { You should know } \\
\text { when things are } \\
\text { small because } \\
\text { they grow big } \\
\text { fast." (FT2.F3) }\end{array}$ & $\begin{array}{l}\text { "I want to be } \\
\text { treated so I can } \\
\text { have a long life, } \\
\text { have less pain, } \\
\text { feel good and do } \\
\text { all my things." } \\
\text { (FT2.D15) }\end{array}$ & $\begin{array}{l}\text { "When I am sick I } \\
\text { come to the } \\
\text { CURAFA }^{\mathrm{TM}} \text { facility } \\
\text { and I am treated by } \\
\text { the doctor. } \\
\text { CURAFA }^{\mathrm{TM}} \text { is my } \\
\text { choice when I } \\
\text { already have the } \\
\text { prescription because } \\
\text { I can come by foot, } \\
\text { it is near."(FT1.Pat } 4 \text { ) }\end{array}$ \\
\hline
\end{tabular}


AIII: The Hard-to-Reach. This archetype illustrates a patient who is disconnected, both technologically as well as socially. It represented $12 \%$ of the conducted persona refinement interviews (60\% male, $40 \%$ female). The priority is to feed the family. For this archetype, one day without working means one day without any food to eat in the evening. Therefore, it is important to reduce the time spent on seeking healthcare. This persona is characterized by low technological literacy. This archetype wants to have sufficient food before spending money on healthcare. As one interviewee stated, "Food is very important. Healthcare and the rest can come later".

This archetype wants to feel supported by a healthcare professional, and wants to be able to know best practices for treating common diseases (e.g. colds). The pain points are (i) spending time on healthcare rather than generating income or providing subsistence for their family, (ii) lack of money to purchase anything beyond food, and (iii) lack of communication with a healthcare provider.

AIV: The Willing-to-Pay. This archetype illustrates a patient who is physically and socially active and strives to lead a healthy life. It represented $12 \%$ of the conducted persona refinement interviews (20\% male, $80 \%$ female). This archetype is relatively well-off financially and willing to pay more for having high quality services that are convenient to access. For instance, there is a preference for taking injections instead of long-term medication, if that means a once-off visit to a healthcare facility.

This archetype wants to have access to high quality healthcare services and use technology to stay in touch with the healthcare provider, wants to feel supported by a healthcare professional when necessary, and wants to be able to receive medical care without losing a day of work (i.e. some patients are shop owners). The pain points are: (i) little availability of medication, (ii) poor access to medical care facilities, and (iii) few healthcare professionals available.

\subsection{Designing Requirements for mHealth Interventions}

These four archetypes present key insights into patients' living conditions in rural Kenya. The needs of these archetypes were subsequently translated into requirements for mHealth interventions in Kenya, illustrated in Table 2.

A common denominator for all four archetypes, suggested by our results, is that, firstly, it is essential to develop a system that is easy to learn and use (CRq1) due to the different literacy levels of patients; secondly, that it should aim to reduce travel time for patients (CRq5) since many either cannot afford to skip work or have difficulties with traveling due to chronic diseases. Moreover, considering that it is difficult and costly for patients and healthcare professionals to meet each other on a regular basis, a fundamental design requirement is to leverage support from the local community (CDRq3), and to provide access to educational content and lifestyle advice related to specific illnesses (CDRq2) to enable a better understanding of diseases and prevention of new ones. Due to the different levels of purchasing power and technology adoption, it is necessary to provide offline functionalities (CRq4). For instance, The Hard-to-Reach only has access to a feature phone, while The Chronically Ill has a smartphone but lacks affordability to purchase data plans. Finally, the interventions should consider the diversity of languages that exist in rural Kenya (CRq6).

Considering that there is no one-size-fits-all solution for digital approaches and that users must be understood and contextualized, requirements that are specific for each archetype were also identified. For instance, when developing an intervention for The Chronically Ill, it is important to enable the patient to have access to medical care treatment on a regular basis (CPDRq1) due to the archetype's serious illness. It is also advisable to provide daily information with a focus on the archetype's disease (CPDRq2), such as direct contact to diet or lifestyle counseling. While such structures cannot replace professional medical advice and treatment, they can help to enhance the reach of medical professionals into rural parts of the country. Access to group support (CPDRq3) is also important considering that this archetype may need reassurance and support to enable habit formation and to understand the side effects of a disease. Finally, it is important to consider that it should be designed for a feature phone (CPDRq4).

In order to develop mHealth interventions targeted to The Family Provider, it is critical to start with the needs of the family (FPRq1). Since The Family Provider wants to feel in control of the healthcare treatment of the family, it is recommended to design an intervention that can offer them the latest update on the family health status from a trusted source (FPRq2). Considering that this archetype has access to a smartphone and might be able to afford a data plan, one way to accomplish this might be by providing push notifications when a family member has a new input from the healthcare professional. Moreover, the business model of the mHealth intervention should offer a family package plan that includes access to the family's health history (FPRq3) and monthly or yearly payments (FPRq4).

When designing mHealth interventions for The 
Table 2: Requirements for mHealth application in Kenya derived from field research

\begin{tabular}{lllll}
\hline Requirements & $\begin{array}{l}\text { Archetype } \\
\text { The Chronically }\end{array}$ & $\begin{array}{l}\text { The Family } \\
\text { Provider }\end{array}$ & $\begin{array}{l}\text { The } \\
\text { Hard-to-Reach }\end{array}$ & $\begin{array}{l}\text { The } \\
\text { Willing-to-Pay }\end{array}$ \\
\hline $\begin{array}{l}\text { Common } \\
\text { requirements }\end{array}$ & $\begin{array}{l}\text { CRq1: Easy to learn and use } \\
\text { CRq2: Integrate an educational concept and lifestyle advice }\end{array}$ & \\
& $\begin{array}{l}\text { CRq3: Leverage support from local communities } \\
\text { CRq4: Provide offline functionalities }\end{array}$ & \\
CRq5: Aim to reduce travel time \\
CRq6: Language openness
\end{tabular}

Hard-to-Reach, it is fundamental to provide services that are aligned with the archetype's work routine (HaRq1). This means that the mHealth intervention should not disrupt a workday since any major disruption might lead to a lack of food for the family. Considering that this archetype is in the lowest financial category compared to all other archetypes, the solution should be cheap (HaRq2). Despite these conditions, mHealth interventions should provide some connection to a healthcare provider (HaRq3) since this archetype wants to feel supported by a healthcare professional. In addition, the mHealth intervention should be designed to be accessible with a feature phone (HaRq4). Finally, an intervention for The Willing-to-Pay should offer access to high quality healthcare services (CRq1) in a convenient way even if that means paying more (CRq2). Similarly to The Hard-to-Reach, it is critical that the solution does not majorly disrupt a workday (CRq4), to avoid income loss. Even though the archetype has a relatively high job income, some patients reported to have their own shop, and if they cannot supervise it, they need to close it. Finally, the design of the intervention should include direct contact with a healthcare provider when necessary (CRq3).

\section{Discussion}

First, the results of the preliminary quantitative study are interesting and need some consideration. Surprisingly, $69 \%$ of patients claimed to be satisfied with their current medical care. This contradicts the results found in the interviews, and those of previous studies that indicate a considerable shortage of healthcare professionals [2] and lack of affordability of medicines [39] in Kenya. Even more surprising, 59\% of participants reported easy access to medical care, which also contradicts the results of the interviews and of previous studies [30, 40, 41]. This contradiction shows the relevance of this study in answering the call of [9, 11] for more studies to go beyond high-level statistical 
data to actually provide an in-depth analysis of specific needs and wishes of the rural Kenyan population.

In answer to RQ2, our findings indicate that when developing mHealth interventions, all requirements are supported by the previously mentioned constructs perceived usefulness, perceived ease of use, perceived cost-effectiveness, and confidentiality. In addition, our findings specify the needs underlying each construct for each archetype. For instance, when considering the construct of perceived cost-effectiveness in mHealth, for the Hard-to-Reach, it is important to develop a cheap solution (HaRq2) that can be used via a feature phone. Whereas, when designing for The Willing-to-Pay, it is important to consider that these users have a higher technology literacy and are willing to pay more for quality and convenience (CSRq2). In this way, our findings not only provide evidence that support technological acceptance models but also goes one step further and expand these studies by presenting more user-centered insights for each construct.

As the use of mHealth becomes increasingly popular, understanding how to leverage user-centered approaches to identify and synthesize patients' motivations and needs for mHealth is drawing more and more attention. Although the sample of this paper is limited to some areas of rural Kenya, our findings offer relevant insights to researchers and practitioners who want to develop mHealth interventions in similar settings. For instance, our study presents evidence of specific user motivations, attitudes, and preferences in rural Kenya that might apply to other RLS - for example, within the rest of Kenya, other African countries (such as neighboring Uganda where TAM-RLS was derived [14]), or other developing countries with similar RLS characteristics.

\section{Conclusion and Limitations}

Through a mixed-method inquiry (surveys and interviews), this study proposes four archetypes for mHealth development that illustrate the variety of health-related needs and the financial-technological context of patients in rural Kenya. Moreover, the needs of each archetype were translated into common and specific design requirements. One clear limitation of this study is that the representation of archetypes illustrates only three counties in rural Kenya. In this case, further studies should investigate the potential for generalizing our findings by investigating different contexts where patients face similar challenges.

Nevertheless, the contribution of this research is twofold. First, this study contributes to the literature on user-centered design aimed at developing digital solutions by presenting how mixed-method data can be leveraged to explore the context, patient behaviors, and preferences of user groups, and to define archetypes that typify a range of user experiences to inform the design and creation of mHealth interventions in developing countries. Secondly, we contribute to practice by translating the needs of the archetypes to functional requirements, which developers would be able to use when designing and developing mHealth interventions for Kenya.

\section{Acknowledgment}

Authors would like to thank the support from the Hasso Plattner Design Thinking Research Program (HPDTRP - Germany), the Institute of Information Management from the University of St.Gallen (IWI-HSG) and Merck Healthcare KGaA.

\section{References}

[1] U. Nations, "Goal 3: Ensure healthy lives and promote well-being for all at all ages," 2020.

[2] K. M. of Health, "Kenya health workforce report: The status of healthcare professionals in kenya," 2015.

[3] T. J. Betjeman, S. E. Soghoian, and M. P. Foran, "mhealth in sub-saharan africa," International journal of telemedicine and applications, vol. 2013, 2013.

[4] C. A. of Kenya, "Fourth quarter sector statistics report for the financial year 2017/2018," 2018.

[5] K. M. of Health, "Kenya national ehealth policy 2016-2030," 2014.

[6] C. B. Aranda-Jan, N. Mohutsiwa-Dibe, and S. Loukanova, "Systematic review on what works, what does not work and why of implementation of mobile health (mhealth) projects in africa," BMC public health, vol. 14, no. 1, p. 188, 2014.

[7] A. Chib, M. H. van Velthoven, and J. Car, "mhealth adoption in low-resource environments: a review of the use of mobile healthcare in developing countries," Journal of health communication, vol. 20, no. 1, pp. 4-34, 2015.

[8] C. Briscoe and F. Aboud, "Behaviour change communication targeting four health behaviours in developing countries: a review of change techniques," Social science \& medicine, vol. 75, no. 4, pp. 612-621, 2012.

[9] K. N. B. of Statistics, "Kenya integrated household budget survey (kihbs) 2015-2016," 2018.

[10] A. Cooper, R. Reimann, and D. Cronin, About face 3: the essentials of interaction design. John Wiley \& Sons, 2007.

[11] V. Haldane, J. J. K. Koh, A. Srivastava, K. W. Q. Teo, Y. G. Tan, R. X. Cheng, Y. C. Yap, P.-S. Ong, R. M. Van Dam, J. M. Foo, et al., "User preferences and persona design for an mhealth intervention to support adherence to cardiovascular disease medication in singapore: A multi-method study," JMIR mHealth and uHealth, vol. 7, no. 5, p. e10465, 2019. 
[12] C. Niemöller, D. Metzger, L. Berkemeier, B. Zobel, O. Thomas, and V. Thomas, "Designing mhealth applications for developing countries," 2016.

[13] K. R. Lienhard and C. Legner, "Principles in the design of mobile medical apps: guidance for those who care," 2017.

[14] J. I. Campbell, I. Aturinda, E. Mwesigwa, B. Burns, J. E. Haberer, D. R. Bangsberg, R. J. Holden, N. C. Ware, and M. J. Siedner, "The technology acceptance model for resource-limited settings (tam-rls): A novel framework for mobile health interventions targeted to low-literacy end-users in resource-limited settings," AIDS and Behavior, vol. 21, no. 11, pp. 3129-3140, 2017.

[15] J. T. Ami-Narh and P. A. Williams, "A revised utaut model to investigate e-health acceptance of health professionals in africa," Journal of Emerging Trends in Computing and Information Sciences, vol. 3, no. 10, pp. 1383-1391, 2012.

[16] F. D. Davis, "Perceived usefulness, perceived ease of use, and user acceptance of information technology," MIS quarterly, pp. 319-340, 1989.

[17] V. Venkatesh, M. G. Morris, G. B. Davis, and F. D. Davis, "User acceptance of information technology: Toward a unified view," MIS quarterly, pp. 425-478, 2003.

[18] V. Venkatesh, J. Y. Thong, and X. Xu, "Consumer acceptance and use of information technology: extending the unified theory of acceptance and use of technology," MIS quarterly, pp. 157-178, 2012.

[19] A. Abubakar, A. Van Baar, R. Fischer, G. Bomu, J. K. Gona, and C. R. Newton, "Socio-cultural determinants of health-seeking behaviour on the kenyan coast: a qualitative study," PloS one, vol. 8, no. 11, p. e71998, 2013

[20] B. I. Ahmad et al., "User acceptance of health information technology (hit) in developing countries: a conceptual model," Procedia Technology, vol. 16, pp. 1287-1296, 2014.

[21] T. Salgado, J. Tavares, and T. Oliveira, "Drivers of mobile health acceptance and use from the patient perspective: Survey study and quantitative model development," JMIR mHealth and uHealth, vol. 8, no. 7, p. e17588, 2020 .

[22] A. J. Deacon, J. Chee, W. Chang, and B. Harbourne, "Mobile applications for diabetes mellitus self-management: A systematic narrative analysis," 2017.

[23] A. Wesolowski, N. Eagle, A. M. Noor, R. W. Snow, and C. O. Buckee, "Heterogeneous mobile phone ownership and usage patterns in kenya," PloS one, vol. 7, no. 4, p. e35319, 2012.

[24] P. R. Center, "Internet connectivity seen as having positive impact on life in sub-saharan africa."

[25] R. E. Bawack and J. R. K. Kamdjoug, "Adequacy of utaut in clinician adoption of health information systems in developing countries: The case of cameroon,' International journal of medical informatics, vol. 109, pp. 15-22, 2018.

[26] A. van Heerden, D. M. Harris, H. van Rooyen, R. V. Barnabas, N. Ramanathan, N. Ngcobo, Z. Mpiyakhe, and W. S. Comulada, "Perceived mhealth barriers and benefits for home-based hiv testing and counseling and other care: qualitative findings from health officials, community health workers, and persons living with hiv in south africa," Social Science \& Medicine, vol. 183, pp. 97-105, 2017.

[27] O. El-Gayar, P. Timsina, N. Nawar, and W. Eid, "A systematic review of it for diabetes self-management: are we there yet?," International journal of medical informatics, vol. 82, no. 8, pp. 637-652, 2013.

[28] F. Petersen, A. Brown, S. Pather, and W. D. Tucker, "Challenges for the adoption of ict for diabetes self-management in south africa," The Electronic Journal of Information Systems in Developing Countries, p. e12113, 2019.

[29] D. Zurovac, A. O. Talisuna, and R. W. Snow, "Mobile phone text messaging: tool for malaria control in africa," PLoS Med, vol. 9, no. 2, p. e1001176, 2012.

[30] K. J. Head, S. M. Noar, N. T. Iannarino, and N. G. Harrington, "Efficacy of text messaging-based interventions for health promotion: a meta-analysis," Social science \& medicine, vol. 97, pp. 41-48, 2013.

[31] B. Fjeldsoe, Y. Miller, and A. Marshall, "Text messaging interventions for chronic disease management and health promotion," E-Health Applications: Promising Strategies for Behavior Change, vol. 1, pp. 167-186, 2012.

[32] M. Njoroge, D. Zurovac, E. A. Ogara, J. Chuma, and D. Kirigia, "Assessing the feasibility of ehealth and mhealth: a systematic review and analysis of initiatives implemented in kenya," BMC research notes, vol. 10, no. 1, pp. 1-11, 2017.

[33] P. Ndayizigamiye and M. Maharaj, "Mobile health adoption in burundi: A utaut perspective," in 2016 IEEE Global Humanitarian Technology Conference (GHTC), pp. 613-623, IEEE, 2016.

[34] J. Pruitt and T. Adlin, The persona lifecycle: keeping people in mind throughout product design. Elsevier, 2010.

[35] A. Cooper et al., The inmates are running the asylum: Why high-tech products drive us crazy and how to restore the sanity, vol. 2. Sams Indianapolis, 2004.

[36] R. J. Holden, A. Kulanthaivel, S. Purkayastha, K. M. Goggins, and S. Kripalani, "Know thy ehealth user: Development of biopsychosocial personas from a study of older adults with heart failure," International journal of medical informatics, vol. 108, pp. 158-167, 2017.

[37] J. W. Creswell and V. L. P. Clark, Designing and conducting mixed methods research. Sage publications, 2017.

[38] D. A. Gioia, K. G. Corley, and A. L. Hamilton, "Seeking qualitative rigor in inductive research: Notes on the gioia methodology," Organizational research methods, vol. 16, no. 1, pp. 15-31, 2013.

[39] W. H. Organization et al., WHO guideline on country pharmaceutical pricing policies. World Health Organization, 2015.

[40] M. Kukla, N. McKay, R. Rheingans, J. Harman, J. Schumacher, K. L. Kotloff, M. M. Levine, R. Breiman, T. Farag, D. Walker, et al., "The effect of costs on kenyan households' demand for medical care: why time and distance matter," Health policy and planning, vol. 32, no. 10, pp. 1397-1406, 2017.

[41] A. Cameron, M. Ewen, D. Ross-Degnan, D. Ball, and R. Laing, "Medicine prices, availability, and affordability in 36 developing and middle-income countries: a secondary analysis," The lancet, vol. 373, no. 9659, pp. 240-249, 2009. 